\begin{tabular}{lcc}
\hline Volume 6 & Nomor 2 & Agustus 2018 \\
\hline
\end{tabular}

\title{
Pengembangan Sistem Informasi Guna Mendukung Pencatatan dan Pelaporan Program Pengendalian Penyakit Diare di Kabupaten Musi Rawas
}

\author{
Arsep Liyenti*, Aris Puji Widodo**, Suhartono*** \\ * Dinas Kesehatan Kabupaten Musi Rawas \\ **Fakultas Sains dan Matematika Universitas Diponegoro Semarang. \\ ***Fakultas Kesehatan Masyarakat Universitas Diponegoro Semarang. \\ Email :y32n4@ymail.com
}

\section{ABSTRACT}

Preliminary surveys that have been carried out indicate the existence of problems in the information system that is currently underway, namely in terms of collecting and processing and analyzing data on diarrheal disease control programs that result in delays, inaccuracies and incompleteness of data and information. This study aimed to develop an information system that can support the recording and reporting of diarrheal disease control programs.

Research conducted using qualitative methods and system development methods is the Framework for Application of System Technique (FAST). Data collected by indepth interviews and observation. The subjects were 3 midwives and 3 managers of diarrheal disease control programs at the Health centers as the main informants and 1 manager of the diarrheal disease control program at the Health Office as the trigulation informant. Data analysed using content analysis.

Development of information systems for recording and reporting diarrheal disease control programs tailored to the needs of users, namely midwives, diarrheal disease control program managers, health centers and health offices, which refers to the reporting format for diarrheal disease control programs. Midwives and managers of the diarrheal disease control program Health centers input patient data and examination results for diarrhea patients using an Android-based cellular phone so that it can be done at the time of the patient's examination directly. This is to overcome delays in collecting data.

It was concluded that the development of information systems for recording and reporting diarrhea disease control programs resulted in systems that assisted in the collection, management and analysis of diarrheal disease control programs. This system can be utilized by midwives, managers of diarrheal disease control programs, health centers and health offices as support in making health policies for diarrheal disease control programs in their respective work areas. 
Keywords : Diarrhea, Information System, Framework for Tecnique Application of System, Recording, Reporting

\section{PENDAHULUAN}

Seseorang mengalami diare apabila seseorang tersbut buang air besar yang melebihi frekwensi lebih sering dari biasanya yaitu tiga kali bahkan lebih dalam satu hari dimana kondisi tinja lembek atau cair dan terkadang dapat berupa air saja. ${ }^{1}$ Berdasarkan data World Health Organization pada tahun 2013, diare merupakan penyakit yang menduduki urutan kedua sebagai penyebab kematian yang menyerang anak-anak dan balita, dimana diare dapat mengakibatkan penderitanya kehilangan banyak cairan dalam tubuh atau disebut dehidrasi. ${ }^{2}$

Di Indonesia penyakit diare merupakan penyakit endemis yang dapat terjadi sepanjang tahun, terutama pada saat pergantian musim sering terjadi peningkatan kasus penyakit diare. Pada tahun 2016 diwilayah kerja Kabupaten Musi Rawas, penyakit diare merupakan kasus tertinggi dengan jumlah kasus sebanyak 8.720 kasus. $^{3}$ Ada beberapa faktor yang mempengaruhi besarnya angka kesakitan akibat penyakit diare diantaranya masih rendahnya perilaku hidup bersih dan sehat, dimana sebagian besar perilaku masyarakat dalam buang air besar yang masih sering dilakukan disungai, sedangkan cakupan ketersediaan jamban diwilayah Kabupaten Musi Rawas sebesar $63,26 \%$. Selain itu cakupan air bersih sebesar $85,80 \%$ yang belum mampu memenuhi kebutuhan masyarakat secara menyeluruh diwilayah Kabupaten Musi Rawas. ${ }^{3}$

Penyakit diare yang juga merupakan suatu penyakit yang berpotensi wabah sehingga dapat menimbulkan kejadian luar biasa penyakit diare. ${ }^{4}$ Untuk mengantisipasi agar hal tersebut tidak terjadi perlu dilakukan pemantauan kasus penyakit diare melalui pencatatan dan pelaporan program pengendalian penyakit diare. Peningkatan kasus diare terjadi diwilayah Kabupaten Musi Rawas pada tahun 2014, bahkan ada penderita yang meninggal dunia. Hal ini disebabkan karena pencatatan dan pelaporan yang tidak terpantau pada bulan sebelumnya dan rekapitulasi laporan yang terlambat dikirim ke Dinas Kesehatan.

Berdasarkan studi pendahuluan, terdapat beberapa permasalahan yang peneliti temukan mengenai sistemi nformasi pencatatan dan pelaporan program pengendalian penyakit diare yang ada saat ini yaitu pengelola mengalami kesulitan dalam mengakses data kembali, informasi yang dilakukan belum lengkap dan tidak tepat waktu.

\section{METODE PENELITIAN}

Pengembangan sistem dilakukan berdasarkan tahapan FAST (Framework for the Application of System Tecniques). ${ }^{5}$ Desain penelitian yang digunakan adalah desain pra eksprerimen dengan pendekatan design posttest. ${ }^{6}$ Subjek penelitian terdiri atas informan utama yaitu Bidan dan pengelola program pengendalian penyakit diare Puskesmas yang diwakilkan 3 Puskesmas dan Informan Triagulasi yaitu pengelola program pengendalian penyakit diare Dinas Kesehatan Kabupaten Musi Rawas. Pengumpulan data dilakukan dngan cara observasi dan wawancara mendalam terhadap pengguna sistem. Analisis data kualitatif dilakukan dengan analisis isi. ${ }^{7}$

\section{HASIL DAN PEMBAHASAN}

\section{Karakteristik Informan}

Karakteristik informan dinilai berdasarkan latar belakang pendidikan dapat dilihat pada tabel 1

Tabel 1 Karakteristik Informan

\begin{tabular}{llll}
\hline \multirow{2}{*}{ No } & \multicolumn{1}{c}{ Informan } & \multicolumn{2}{c}{ Pendidikan } \\
\cline { 3 - 4 } & & DIII & S1 \\
\hline 1 & Bidan (IU) & 3 orang & \\
\hline 2 & Pengelola Program & 2 orang & 1 orang \\
& Diare Puskesmas (IU) & & \\
\hline 3 & Pengelola Program & & 1 orang \\
& Diare Dinas & & \\
& &
\end{tabular}


Berdasarkan tabel 1 diperoleh informasi bahwa informan yang memiliki latar belakang pendidikan terendah (DIII) sebanyak 5 orang sedangkan informan yang memiliki latar belakang pedidikan tertinggi (S1) 2 orang, sehingga hal ini dapat menyimpulkan bahwa pendidikan infoman sudah cukup baik. Tingkat pendidikan mempunyai pengaruh yang signifikat terhadap kualitas kinerja serta pemahaman pekerja/pengelola program.

Dalam penelitian ini tingkt pendidikan yang baik dari masing-masing informan memudahkan peneliti pada saat sosialisasi dan pelatihan terhadap sistem informasi yang dikembangkan.

\section{Gambaran Umum dan Permasalahan} Sistem Informasi Pencatatan dan Pelaporan Program Pengendalian

$\begin{aligned} & \text { Penyakit Diare Sebelum } \\ & \text { Dikembangkan }\end{aligned}$
Sisem

Sistem informasi pelaporan dan pencatatan program pengendalian penyakit diare sebelum dikembangkan di Kabupaten Musi Rawas belum terkomputerisasi dengan baik. Pengelola program pengendalian penyakit diare Puskesmas megumpulkan hasil kegiatan bulanan dari bidan yang berada di Polindes dalam wilayah kerjanya kemudian laporan tersebut direkapitulasi dengan laporan di Puskesmas. Hasil rekapitulasi laporan tersebut dilaporkan dan dikirim ke Dinas Kesehatan dengan batas waktu setiap tanggal 5 pada bulan bulan berikutnya. Laporan bulanan yang diterima dari masing-masing Puskesmas tersebut dilakukan rekapitulasi oleh pengelola program pengendalian penyakit diare Dinas Kesehatan, yang akan dilanjutkan pelaporan tersebut ke Dinas Kesehatan Propinsi.

Pencatatan dan pelaporan yang ada merupakan data dasar yang mempunyai peran penting dalam pemantauan dan evaluasi program pengendalian prnyakit diare oleh karena itu diharapakan data yang ada tersebut telah lengkap, akurat dan tepat waktu. $^{8}$ Data atau informasi tersebut diperoleh secara berjenjang dari bidan hingga ke pusat yang terjadi tiap bulannya.

Masih ditemukan beberapa permasalahan yang ada pada sistem informasi sebelum dikembangkan yaitu data yang tersimpan masih dalam bentuk file lembaran yang mengakibatkan akses yang sulit untuk memperoleh data kembali dan belum tersedianya basis data dalam pengolahan data, untuk mendapatkan informasi seperti sebaran kasus diare per desa dibutuhkan tambahan waktu sehingga informasi yang diperoleh tersebut tidak tepat waktu sebagaimana mestinya, perhitungan realisasi penemuan kasus tidak bisa dilakukan secara otomatis dan sering terjadi penggulangan dalam input data yang dapat menimbulkan kesalahan sehingga data yang dihasilkan tidak akurat, informasi yang dihasilkan hanya dalam bentuk tabel sehingga informasi yang ada menjadi kurang jelas.

\section{Sistem Informasi Pencatatan dan} Pelaporan Program Pengendalian Penyakit Diare Setelah Dikembangkan

Permasalahan yang terdapat pada sistem informasi yang lama dapat diatasi dengan dilkukan sebuah pengembangan sistem informasi yang apat mendukung pencatatan dan pelaporan program pengendalian penyakit diare yang terkomputerisasi serta menggunakan sistem manajemen basis data yang dapat memudahkan pengguna dalam mengakses data dan informasi. Data dan informasi yang disajikan tidak hanya dalam bentuk tabel tetapi juga dalam bentuk grafik. Sistem informasi yang akan dikembangkan mengacu pada prosedur sistem informasi yaitu mempunyai input, proses dan output. ${ }^{9,10}$ Sistem informasi juga berbasis web untuk 
mengatasi permasalahan keterlambatan pelaporan bidan dan juga pengelola program pengendalian penyakit diare Puskesmas.

Secara lengkap diagram konteks sistem informasi pencatatan dan pelaporan program pengendalian penyakit diare dapat dilihat pada gambar 1 dan ERD dapat dilihat pada gambar 2.

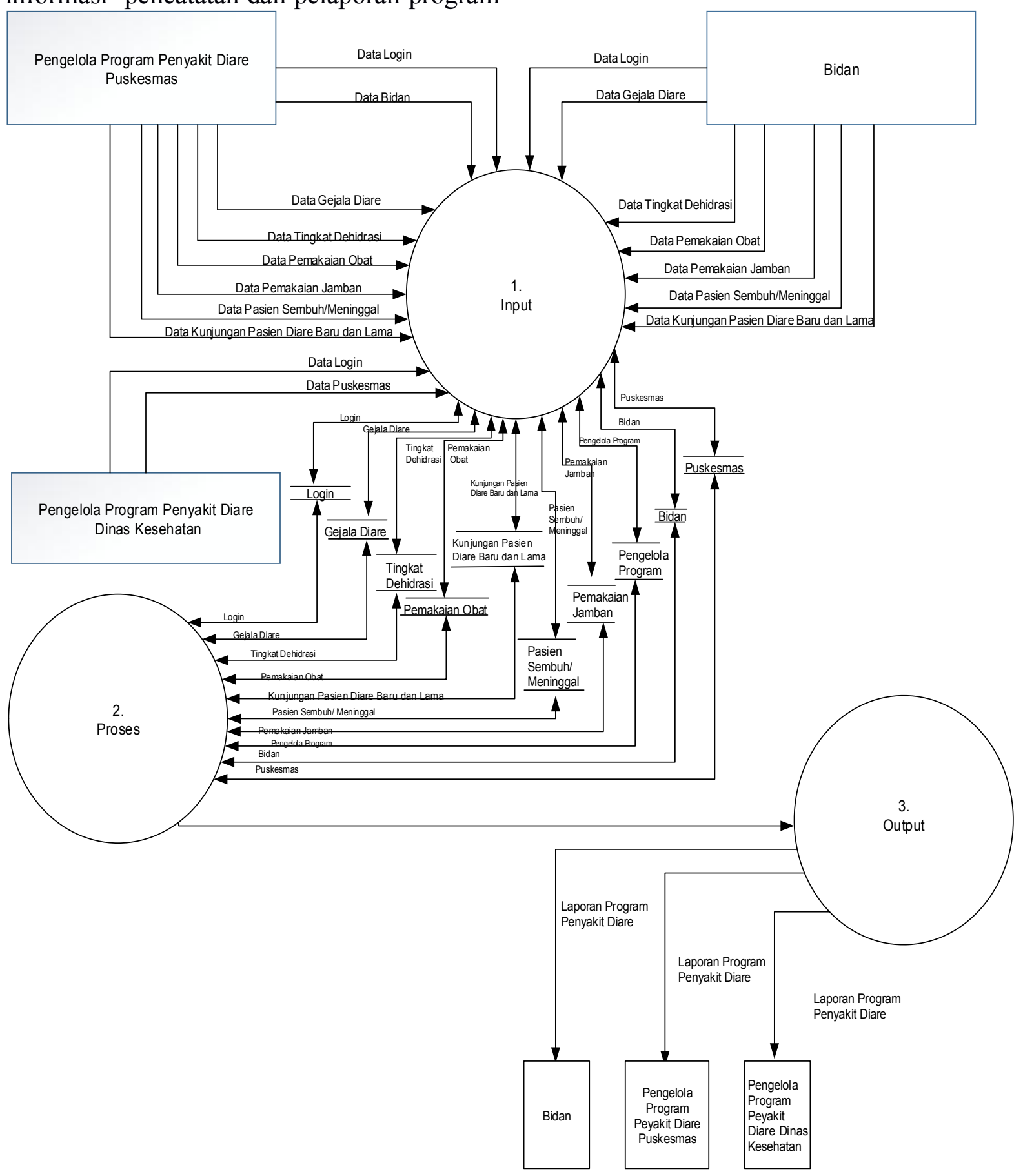

Gambar 1 Diagram Konteks Sistem Informasi Pencatatan dan Pelaporan Program Pengendalian Penyakit Diare 


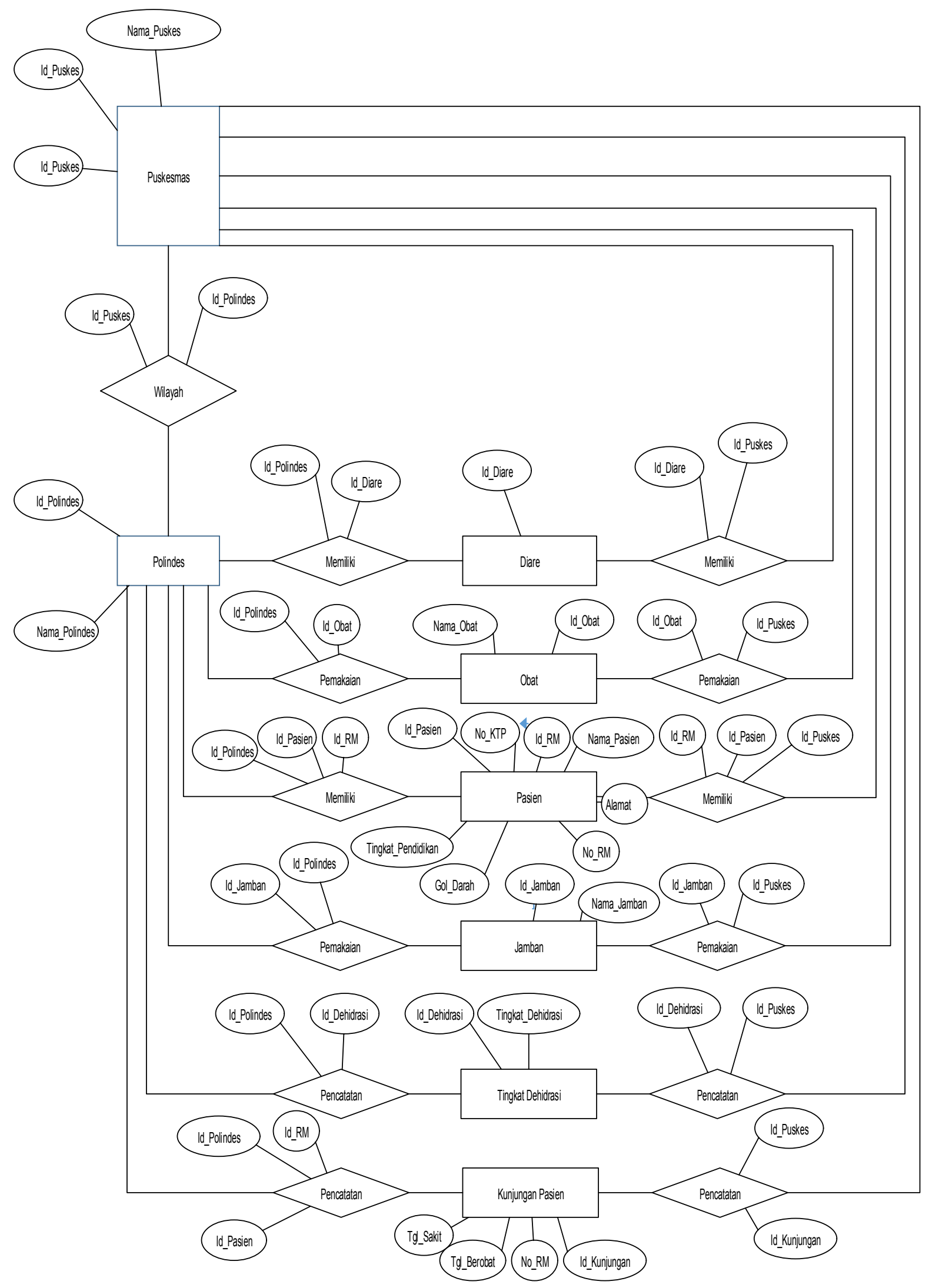

Gambar 2 ERD Sistem Informasi Pencatatan dan Pelaporan

Program Pengendalian Penyakit Diare 
Tabel 2 Output Sistem Informasi yang Telah Dikembangkan

\begin{tabular}{|c|c|c|c|c|c|}
\hline No & Jenis & Format & Media & Alat & Distribusi \\
\hline 1 & $\begin{array}{l}\text { Pencatatan registrasi harian } \\
\text { penderita diare }\end{array}$ & $\begin{array}{l}\text { Tabel } \\
\text { dan } \\
\text { Grafik }\end{array}$ & Kertas & Printer & $\begin{array}{ll}\text { pengelola } & \text { program } \\
\text { pengendalian } & \text { penyakit } \\
\text { diare Puskesmas }\end{array}$ \\
\hline 2 & $\begin{array}{l}\text { Pencatatan mingguan penderita } \\
\text { diare }\end{array}$ & $\begin{array}{l}\text { Tabel } \\
\text { dan } \\
\text { Grafik }\end{array}$ & Kertas & Printer & $\begin{array}{l}\text { pengelola program } \\
\text { pengendalian penyakit } \\
\text { diare Puskesmas }\end{array}$ \\
\hline 3 & $\begin{array}{l}\text { Pencatatan laporan bulanan } \\
\text { program diare akumulasi } \\
\text { diwilayah kerja Puskesmas }\end{array}$ & $\begin{array}{l}\text { Tabel } \\
\text { dan } \\
\text { Grafik }\end{array}$ & Kertas & Printer & $\begin{array}{ll}\text { Pengelola } & \text { program } \\
\text { pengendalian } & \text { penyakit } \\
\text { diare Puskesmas }\end{array}$ \\
\hline 4 & $\begin{array}{l}\text { Pencatatan Laporan bulanan } \\
\text { program diare akumulasi } \\
\text { diwilayah kerja Dinas Kesehatan }\end{array}$ & $\begin{array}{l}\text { Tabel } \\
\text { dan } \\
\text { Grafik }\end{array}$ & Kertas & Printer & $\begin{array}{l}\text { Pengelola program } \\
\text { pengendalian penyakit } \\
\text { diare Dinas Kesehatan }\end{array}$ \\
\hline 5 & $\begin{array}{l}\text { Pencatatan laporan tahunan } \\
\text { program diare akumulasi } \\
\text { diwilayah kerja Puskesmas }\end{array}$ & $\begin{array}{l}\text { Tabel } \\
\text { dan } \\
\text { Grafik }\end{array}$ & Kertas & Printer & $\begin{array}{ll}\text { Pengelola } & \text { program } \\
\text { pengendalian } & \text { penyakit } \\
\text { diare Puskesmas }\end{array}$ \\
\hline & $\begin{array}{l}\text { Pencatatan Laporan tahunan } \\
\text { program diare akumulasi } \\
\text { diwilayah kerja Dinas Kesehatan }\end{array}$ & $\begin{array}{l}\text { Tabel } \\
\text { dan } \\
\text { Grafik }\end{array}$ & Kertas & Printer & $\begin{array}{l}\text { Pengelola program } \\
\text { pengendalian penyakit } \\
\text { diare Dinas Kesehatan }\end{array}$ \\
\hline
\end{tabular}

\section{Output yang dihasilkan sistem}

Secara lengkap output yang dihasilkan oleh sistem informasi yang telah dikembangkan dapat dilihat pada tabel 2 .

Output yang diperlihatkan pada tabel 2 merupakan hasil wawancara dan telah didiskusikan antara peneliti dan pengguna sistem yang menghasilkan laporan, baik dalam bentuk tabel dan grafik berdasarkan kebutuhan masing-masing pengguna untuk mendukung pencatatan dan pelaporan program pengendalian penyakit diare.

\section{Uji Coba Sistem Informasi Yang Telah Dikembangkan}

Sistem informasi pencatatan dan pelaporan program pengendalian penyakit diare yang telah dikembangkan dilakukan uji coba di Dinas Kesehatan Kabupaten Musi Rawas dan 3 Puskesmas. Sebelum dilakukan uji coba, dilakukan sosialisasi terlebih dahulu tentang sistem informasi yang baru serta manfaat nya kepada pengguna sistem, kemudian dilakukan pelatihan beberapa kali yang bertujuan untuk melatih pengguna sistem agar paham dalam mengoperasikan sistem tersebut. Sosialiasi dan pelatihan dilakukan dengan cara mendatangi Dinas Kesehatan Kabupaten Musi Rawas serta Puskesams yang dijadikan sampel uji coba sistem yang dikembangkan.

\section{KESIMPULAN}

Pengembangan sistem informasi pencatatan dan pelaporan program pengendalian penyakit diare dapat diakses menggunakan web atau localhost dengan instalasi sistem ke perangkat keras terlebih dahulu. Selain mampu mendukung pencatatan dan pelaporan program pengendalian penyakit diare, sistem ini juga dapat digunakan sebagai pendukung pengambilan keputusan di tingkat Dinas Kesehatan.

\section{UCAPAN TERIMAKASIH}

Penulis mengucapkan terima kasih kepada MIKM FKM UNDIP dan Dinas 
Kesehatan Kabupaten Musi Rawas atas diijinkannya melakukan penelitian ini.

\section{DAFTAR PUSTAKA}

1. Kementerian Kesehatan Republik Indonesia. Direktorat Pengendalian Penyakit dan Penyehatan Lingkungan. Buku Pedoman Pengendalian Penyakit Diare. Jakarta: Kemenkes RI; 2011.

2. World Health Organization. Diarrheal Disease. Genva: WHO; 2013.

3. Dinas Kesehatan Kabupaten Musi Rawas. Profil Kesehatan Kabupaten Musi Rawas Tahun 2016. Muara Beliti; 2017

4. Kementerian Kesehatan Republik Indonesia. Direktorat Pengendalian Penyakit dan Penyehatan Lingkungan. Buku Saku Lintas Diare Untuk Petugas Kesehatan. Jakarta: Kemenkes RI; 2015.

5. Whitten, Bently D. Metode Desain dan Analisis Sistem Edisi 6. Yogyakarta: Andi Offset; 2004.

6. Prihartono J. Metodologi Penelitian: Kedokteran dan Kesehatan Masyarakat. Jakarta: Binarupa Aksara; 2003.

7. Sugiyono. Metode Penelitian Kuantitatif Kualitatif dan R\&D. Bandung: Alfabeta; 2014.

8. Winarno. Sistem Informasi Manajemen. Yogyakarta: Penerbit UPP AMP YKPN; 2004.

9. Nazruddin. Pemograman Aplikasi Mobile Smartphone dan Tablet PC Berbasis Android. Bandung: Informatika; 2013.

10. Kristanto.A. Perancangan Sistem Informasi dan Aplikasi. Jakarta: Gaya Media; 2003. 